https://doi.org/10.32735/S0718-2201202100053941

\title{
GUSTAVO OTT, EL ESPECTÁCULO COMO ESTÉTICA DE LA ALTERIDAD
}

Gustavo Ott, the spectacle as aesthetics of otherness

\author{
KARENGONZÁLEZHENRÍQUEZ \\ Universidad de la Costa (Colombia) \\ kgonzale8@cuc.edu.co \\ JENIFER MONSALVOLUGO \\ Universidad de la Costa (Colombia) \\ jmonsalv@cuc.edu.co
}

\section{Resumen}

Este trabajo tiene como fin analizar el teatro como una representación de los conflictos del ser y su relación con el mundo. Se centra en el teatro de Gustavo Ott, para quien el Espectáculo es la Alteridad de la sociedad contemporánea, sus obras dramáticas plantean en el tema y la puesta en escena conflictos existenciales del hombre, así como la violencia, la muerte, lo absurdo, lo oscuro, la crueldad y el humor. Por ello, la investigación pretende describir cómo el autor estetiza la violencia y experimenta puestas en escenas teatrales con la literatura y el cine, utilizando teorías y de La Alteridad de M. Bajtín; La Sociedad del Espectáculo, M. Vargas Llosa y El Cine de Q. Tarantino, por medio de una investigación cualitativa, con lectura analítica y amplios registros documentales.

Palabras clave: Teatro; yo-otro; alteridad-cultura-sociedad; espectáculo.

Abstract

This article is intended to analyse the Teatro, As A Representation of the conflicts of the self and its relationship with the world. Search the Through the actors--the characters, the Other being no more than the Self, evidencer A Concienc Cultural heritage in a Show society. The Research focuses on the theatre of Gustavo Ott, for whom The Show is la Alteridad of contemporary SocietyTheir Dramatic works Pose in the subject and staging existential conflicts of man, as well as Violence, death, the Absurd, the dark, the cruelty And The humour. Therefore, the article intends to describe as the author merely aestheticised the violence and experiments in theatrical scenes with literature and cinema, using Theories and methods of La Alteridad of M. Bakhtin; La Sociedad of the Show, M. Vargas Llosa, The Cinema of Q. Tarantino, Through qualitative research, with analytical reading and extensive documentary records.

Key words: Theatre; I-other; alterity-culture-society; show.

\section{INTRODUCCIÓN}

La cultura del siglo XXI es conocida como una cultura del espectáculo, en la que internet, la televisión satelital y el cine en 3D son los medios de comunicación 
predominantes (González y Torres, 2017), no solo por su fuerza en la imagen, en las redes semánticas y en el fácil acceso, también por su rápida comprensión del individuo virtual que se formó y evolucionó con el siglo. "La ilusión de la mentira convertida en verdad ha copado la vida social, convirtiéndola en una representación en la que todo lo espontáneo, auténtico y genuino -la verdad de lo humano- ha sido sustituido por lo artificial y falso" (Debord, 1967, p.7).

En esta sustitución de lo real, ¿Cómo se representa el teatro? Si sabemos que de por sí este es ficción de la realidad humana. Pues allí, radica el gran reto para los creadores y actores de este género en el siglo XXI, porque no pueden caer en incongruencias y exquisiteces egoístas, deben prepararse para ser el Otro que desde lo artificial y falso quiere conocer algo verdadero y real, quiere verse a sí mismo en escena y tomar la voz de los personajes que le den sentido a su ilusoria humanidad.

Se puede decir que, existe una necesidad de representación en el Yo y el Otro que enmarca al público de hoy, porque la escena teatral es una alteridad que compite no solo con la velocidad y rapidez de las comunicaciones, sino también con el tema, la imagen y el entretenimiento que se ofrece en la actualidad.

Por tanto, ¿Qué preocupaciones tiene el teatro contemporáneo? ¿Acaso está consciente de esta verdad? En América, aun se siguen presentando temas, técnicas y formas que responden a las necesidades de otros tiempos, en los que el realismo crítico daba a conocer al sujeto atormentado por su entorno violento y su realidad corrupta, como lo expresa Zuluaga (2016) al referir lo que hizo el artista colombiano a inicio de los veinte, el que "compromete su obra con el porvenir dinámico de la sociedad que habita (...) respecto de todos aquellos que experimentan directamente el proceso abrupto que se vive con el nacimiento del país urbano" (p. 78). En nuestros días se evidencia, en países latinoamericanos, que continúa esta realidad latente, tanto, que la violencia y corrupción se hacen espectáculo por medio que de películas y series de las cuales el público disfruta, sin reflexionar que las situaciones representadas hacen parte de su cotidianidad.

Sin embargo, emerge una dramaturgia que ha crecido con el siglo y de a poco ha comprendido las realidades del momento. Entre sus representantes se encuentra Gustavo Ott, quien sostiene desde sus inicios una relación con el realismo crítico en el que se da a conocer la violencia, lo oscuro, lo cruel, pero a su vez ha despertado a la influencia de los medios de comunicación, de la banalidad, de la comercialización, del espectáculo que es lailusión del tiempo.

Se puede decir que Ott incluye en su escritura la angustia, el horror, la violencia, el terrorismo, lo frívolo, lo comercial y los problemas existenciales que cubren a la sociedad de este siglo, que hablan de ese Yo-Otro que se hace alteridad en la representación y en el drama. Es el espectáculo el lugar de encuentro entre la profundidad, la contradicción y la alteridad que pone a la palestra este creador mediante su estética. En este contexto, este artículo busca estudiar en el teatro de Gustavo Ott la Alteridad como 38 | Alpha No 53 (Diciembre 2021) PÁGs. 37-48. ISSN 07 16-4254 
Espectáculo en la construcción de identidades culturales, desde teorías y métodos de la filosofía, la semiología, la cultura del espectáculo, del cine y del teatro.

\section{ELPERSONAJECOMO YO Y OTROENLA ALTERIDADY EL ESPECTÁCULO}

En el teatro podemos observar la polifonía y dialogía entre el Yo y el Otro que muestra lo que está fuera y dentro que a su vez es discurso social en arte del dramaturgo en el Yo y el Otro en forma concomitante, en la que el Yo busca su identidad y el Otro que se identifica en la cultura y la sociedad; para todo ello, en la obra se pone de manifiesto la palabra que se expresa por medio de los personajes, lo que permite ver y escuchar las voces en el espectáculo (representación), las voces de la alteridad.

Con la palabra del personaje (que es la palabra de un tú o del yo del otro), no se pretende presentar la realidad objetiva de su existencia, sino el modo en que dicho personaje concientiza su realidad yreflexiona respecto de símismo en relación con los demás (Bajtin, 1982, p. 41).

El discurso literario toma cuerpo desde la palabra del autor $(Y o)$, que identifica la palabra del Otro y la hace suya para expresarse y con ello dar realidad al discurso ajeno desde la alteridad. En otras palabras, el autor responde, reacciona, asume el planteamiento de otros, cuando construye y crea realidades de relación consigo mismo y con los demás.

La forma artística, es decir la palabra del dramaturgo, organiza los contenidos de la palabra y de la vida propia y ajena, y en la palabra del texto y la representación, la alteridad en la que el personaje resulta convincente, pues, es también diálogo con los espectadores quienes presentizan la alteridad de la que forman parte como miembros de una cultura para que el contenido resulte real y se dé una verosimilitud de valores (Bajtin, 1982, p. 196).

$\mathrm{El}$ autor, director y actores razonan acerca de la palabra como realidad y manifestación del Otro, que en un dinamismo constante involucra diversas conciencias: la conciencia propia y la que contemplan en las vidas ajenas que se convierten en vida propia para el personaje; por cuanto, el Yo representa al autor que se hace Otro en la conciencia del personaje, quien se involucra en interactividad que interpreta la obra y representa la alteridad en la conciencia y en el diálogo interior de la palabra: "El autor por tanto no habla del personaje sino con el personaje" (p. 294).

En este sentido, el personaje no solo revela la voz del sujeto sino a la vez la existencia de su entorno, constituyendo una significación respecto de sí mismo y del mundo. Esto no pudiera representar una realidad objetiva de la existencia, pero si la forma en que el personaje concientiza su realidad y reflexiona acerca de sí mismo en relación con los demás, porque el Otro de Bajtin (que es el personaje) edifica y hace posible el Yo del autor o dramaturgo y la alteridad de la que en diálogo entran ambos. 
La actividad estética no puede darse sin la alteridad, de modo que hay que preguntarse ¿Hasta qué punto habla el autor o el personaje? Esa relación autor-personaje solo encuentra respuesta en la visión del héroe que reconoce el propio teórico "Cuando surge el héroe como un 'Yo', entonces el autor se erige en otro para dar a su héroe un acabado estético, imposible de lograr con el yo especular empírico, porque yo no existo para mí en términos estéticos" (p. 22).

Relación que incorpora Ott en uno de sus personajes que por medio de la representación y las palabras erige esa función del creador estético y pone en su voz la teoría de alteridad en la que reconoce que escribe para por medio de su Yo dar a conocer la vida del Otro:

JUAN: Por eso creo que comencé con lo delteatro: para imaginar gente que pudiera ver o mejor, para vivir la vida que otros vivieron, como dijo un poeta. Pero no una vida repetida todas las noches, sino más bien la vida de personajes en un teatro de la creación continua, en el que cada función no solo es distinta, sino nueva, recién creada (Ott, 2013, p. 23).

De esta manera, el autor existirá siempre desde el Otro, porque este Otro es la primera condición del $Y o$; es un reconocerse y realizarse en los actos propios pero en busca de la aprobación del Otro, es decir, se vive en el mundo, de allí que el autor termine por convertirse en el Otro de su héroe. En palabras de Bajtin (2000): "No soy quien mira desde el interior de mi mirada al mundo, sino que yo me veo a mí mismo con los ojos del mundo, con los ojos ajenos, estoy poseído por el otro (...) Desde mis ojos están mirando los ojos del otro" (p. 156).

Esos ojos reconocen los actos propios y aquellos que buscan la aprobación del Otro, además reconocen esas frustraciones del Otro y las hace visible al apoderarse por completo de eso Otro con dialogismo en el Yo, como sucede al personaje de Carlos Fernando que en su confesión al público expresa:

CARLOS FERNANDO: Mi hijo quiso ser pintor. Artista. Pero en nuestra familia si no eres abogado o doctor, lo mejor es que te metas un tiro en la cabeza o te vayas para Nueva York, como hice yo. Fíjate que a Fernando le hicieron la vida imposible porque le gustaba el beisbol. Pero nada, esa era su pasión y murió por ella. Y creo que hizo bien, a pesar de lo que le ha sucedido, porque hoy en día nadie muere por lo que quiere. La mayoría muere sin haber hecho con su vida lo que realmente querían (Ott, 1996, p.12).

Es así como el autor concebido desde los términos de Bajtin es en sí mismo el personaje Otro, que está constituido desde el Yo del autor, en nuestro caso Gustavo Ott, su conciencia y las otras conciencias, de su ajeno, de su contexto y realidad, pero que 
al encontrarse en la alteridad se convierte en acto estético, en obra acabada, en espectáculo y ficción.

El texto teatral representa esta alteridad dialógica en la que el autor reconoce la conciencia del Otro en la conciencia de sí y por medio de la creación deja autonomía al Otro en voz del personaje desde su propia voz; es decir, en el teatro el personaje concebido desde la conciencia del dramaturgo, se manifiesta como identidad del Otro que se encuentra en diálogo con el espectador, el que busca en su propia peculiaridad del texto para la representación reconocerse en los personajes, en los signos que recrean, en los diálogos, en las acciones, porque ellas en polifonía revelan la alteridad, el mundo del lector-espectador y el del Otro y las conciencias, diálogo y contradicciones dialécticas.

En el caso de Ott nos encontramos que su Yo en personaje representado entra en diálogo involucrado como autor y personaje haciendo tesis, que en teoría bajtiniana se cumple en el reconocimiento del Yo en el Otro en dialogía de conciencias, aquí referido a la ficción como dimensión de vida más allá del texto, la representación y la obra: el autor es en sus personajes su conciencia, sus conciencias.

JUAN: Me desperté esta mañana y fue cuando me di cuenta. El teatro es sinépocas, sin tiempo. Es igual al espacio. Todo ocurre al mismo tiempo. Lo mismo sucede con el autor y sus personajes. No somos autores de una pieza, sino de una obra completa, que no termina hasta que terminemos nosotros (Ott, 2013, p. 40).

Para Ott, el teatro en la ficción es la representación de la realidad, visto de esta forma, toda obra teatral por medio de la creación estética, en la que el autor en dialogía mientras tanto abandona su propio eje axiológico para interactuar con y recrear Otro, es el lugar de la alteridad y donde nace la obra.

\section{ELESPECTÁCULO:CONTEMPLACIÓN DEL YO EN EL OTRO COMO REALIDADRECREADA}

La sociedad de la contemporaneidad está marcada por la cultura del espectáculo, que se centra en el consumismo y el entretenimiento del sujeto postmoderno, el que dio un vuelco en su pensamiento y vive del momento, de lo instantáneo, lo fingido y no de lo perdurable; por ello, este se encuentra marcado por las tecnologías, la sustitución de la palabra por la imagen-sonido y el olvido de lo íntimo y propio por lo público y ajeno, todos elementos del espectáculo. El mundo ha cambiado, el espectador "se convierte en un mero consumidor acrítico de ciertos productos culturales que se difunden mediante la prensa escrita o la televisión, entre otros medios de comunicación" (Fernández-Cozman, 2017).

Dentro de esta perspectiva, la cultura entendida como el conjunto de actividades que permiten un estilo de vida de la humanidad ha sufrido una influencia de masas en los últimos 20 años que lleva a sus sujetos al espectáculo, pero a un espectáculo visto desde la representación, a tal extremo que reemplaza el vivir por el representar. Es decir, se vive 
para representar el papel que exige la sociedad y la cultura mediante los medios de comunicación, ya sea el de productor, espectador, imitador o comprador.

El mundo entró al siglo XXI globalizado, los satélites, la TV, las señales radioeléctricas comunican en tiempo real a los habitantes del planeta, la masificación de la cultura es un signo del nuevo siglo que trajo consigo también un nuevo mundo, cambiaron de manera radical los paradigmas de la modernidad y con ellos todos los pueblos del mundo que entraron a definirse en formas y contenidos en una nueva civilización: la civilización del espectáculo.

El bienestar, la libertad de costumbres y el especio creciente ocupado por elocio en el mundo desarrollado constituyeron un estímulo notable para que se multiplicaran las industrias de la diversión, promovidas por la publicidad, madre y maestra mágica de nuestro tiempo (Vargas Llosa, 2012, p. 34).

Visto de esta forma, para la cultura imperante divertirse, escapar del aburrimiento, es la pasión universal, porque el llamado es al olvido de lo profundo, de lo complejo y a la imposición de lo banal y frívolo.

Estas premisas dictaminan el objetivo principal de la sociedad como espectadora, vive del espectáculo y tiene como valores predominantes la frivolidad, pero esto no debe verse como superfluo o ligero, sino que de forma contradictoria tiene una profundidad mayor en la vida contemporánea, ¿podría pensarse entonces en una sociedad sin sentido de la trascendencia? Al respecto, Vargas Llosa (2012) indica que:

La frivolidad consiste en tener una tabla de valores invertida o desequilibrada en la que la forma importa más que el contenido, la apariencia más que la esencia y en la que el gesto y el desplante -la representación- hacen las veces de sentimientos e ideas (p. 51).

Estas consideraciones involucran la realidad que se impone a los sujetos contemporáneos y la importancia de la apariencia en lugar de la esencia, situación que se refleja a diario en la televisión, radio, internet, y cine; pareciese que impera el valor de la imagen, el gesto y lo que representa en dialogía con el Yo y Otro también del espectador. Tal como lo denotan las prácticas de moda, realitys show, farándula e incluso entretenimientos deportivos, sexuales y violentos en los nuevos formatos creados por la tecnología de las telecomunicaciones, la tv, videos y cine que tienen como fin primero y último entretener, divertir y olvidar, esa es la formación y la conciencia.

Ahora bien, estas características del espectáculo permiten reconocer que los valores pasan a su opuesto, y por tanto la realidad se constituye en su oposición, en lo creado, imaginado, en el espectáculo mismo que se convierte en la realidad de quien participa en él. De esta forma, el individuo vive por medio de la vida de sus artistas favoritos, que no son solo los de la novela, series de TV, cantantes, comediantes, sino 
celebridades del mundo de la belleza en concursos, diseñadores de moda, deportes y deportistas, que más que artistas, son personajes de ficción con la investidura de héroes que por sus hazañas pasan a la ficción colectiva masificada.

En el caso de Gustavo Ott, quien reconoce en su dimensión la necesidad de la sociedad del espectáculo y a su espectador como víctima de la barbarie en búsqueda de una compañía para su angustia, él justifica la realidad desde el hecho que la globalización y el Siglo de la Bestia trajo consigo "el aliento de una serpiente como medida del siglo", y por ello el sujeto necesita un creador que represente su horror, la destrucción y la crisis que vive el mundo contemporáneo.

Ya basta de solo disfrute y placer, es necesario el compromiso, la autocrítica, el sentido en aquello que se ofrece como realidad espectacular, como alteridad; por lo que Ott hace una crítica al teatro para que tome esa labor y considere el renacimiento del siglo XXI desde la escena. Para este dramaturgo el espectador...

....sigue sorprendentemente apoyando a su teatro y si uno ve cómo es la calidad de la educación en nuestro país y los suma a los porcentajes de deserción, pues no deja de asombrar que nuestro público sea fundamentalmente joven. Es un milagro, algo que quizás pueda explicar la Iglesia, pero no yo. ¿Cómo existe un público para el teatro en una sociedad globalmente ignorante y desinteresada? Te juro que no lo sé. (Mujica, 2005, p. 3).

El poder quiere desactivar el pensamiento, en lo que coincide con Vargas Llosa, quien afirma que se sugiere trascender, pero sin riesgo, desde el fingimiento. Sin embargo, discrepa de él al considerar que existe una lucha por combatir esta realidad, y lleva el tema en la televisión, en la web y en sus hombros desde el teatro.

Dentro de esta perspectiva, refiere la importancia de la poesía del drama, en la que se debe dar sentido a la palabra desde todas las formas de uso que le da el espectáculo, en el que la imagen es también acción, sentido, icono que es texto, signo, metáfora y símbolo en la alteridad y en la representación teatral. Esta opinión es parte de su teoría e ilustra el argumento anterior. "... hoy tenemos que hablar del tema y darle un efecto de impacto con el símbolo” (Ott, 2009, p.49).

En palabras de este dramaturgo se plantea la crítica social con temas de la cultura como modelos que corresponden a las aspiraciones y a los sueños con los que habitan los miembros de la sociedad y que se convierten en ficciones dentro de sus propias vidas, representadas en el teatro, pero que corresponden a arquetipos culturales formados en los espectáculos en los que los héroes, casi irreales, de ficción como lo son las celebridades del deporte, el cine, la música, los videos, las series, son modelos que Ott, en sus temas, fábulas escénicas y en la representación es sustancia estética.

Es así como nos encontramos a este dramaturgo con teorías, temas, obras y puestas en escena, frente a los nuevos tiempos, de cara al hombre y a la sociedad con la necesidad de dar al teatro nuevos contenidos, porque el mundo cambió de manera abismal, y el 
teatro, según la visión crítica fundamentada por este creador, fue y sigue siendo la víctima predilecta de la Restauración, porque no comprendieron y trataron de encubrir (siglo XX Barbárico). El siglo XXI, sin embargo, ha llegado con percepciones claras acerca de la crisis y la destrucción del siglo que le antecedió, caracterizándolo como Monumentos y lugares del imaginario paranoico colectivo global. Es lo que identifica como Renacimiento en el Siglo de La Bestia.

\section{VIOLENCIA Y GÉNERO NEGRO. TEATRO Y ESPECTÁCULO}

Entre las nuevas formas de representar al hombre actual en sus problemas existenciales, "la maldad del Siglo", los creadores buscan formas que, en la Alteridad social, conforman el tejido cultural en las realidades que en acciones y conciencias son compartidas como víctimas y victimarios. Representaciones que cual simulacros son textos, fábulas en las metáforas de sus vidas, pero que convierten en discurso estético la fealdad, desde lo más oscuro y reprimido del hombre; porque también esto es recurso para el espectáculo y se muestra desde la actitud estética, desde aquello que causa el placer de lo bello, distancia de contemplación de la que hablaba Kant (1984); distancia de "desinterés" o distancia psíquica de la exhibición que se da a conocer al espectador.

El distanciamiento no implica no mencionar la crueldad del hombre, es más bien considerar la ficción para recordarle al individuo que pertenece a esa sociedad cruel en la que la muerte y violencia son espectáculo disfrutable, como lo hace Ott (2013) mediante la dialogía de conciencia que presentan sus personajes:

PADRE: Esos que gritan más fuertes, esos que matan más, esos que hablan de guerra son los que más asustados están. ¿Sabes por qué hijo? Porque están atraídos por el abismo ¡Lo imaginan, lo ven y lo persiguen! ¡Y si no lo pueden ver, entonces lo construyen!

JUAN: ¿El abismo? ¿Lo construyen? ¿Por qué?

PADRE: Porque tienen miedo y son unos cobardes. Uno puede tener miedo, pero al mismo tiempo ser valiente. Pero los que matan, los que les gusta el terror, tienen miedo y son cobardes. Por eso aman el abismo y en su antesala se instalan, contemplando el vacío. Siempre hay que estar contra toda opresión y tiranía, Juan. Las ideas sirven para eso: ¡para derrotar el abismo! ¡Para estar contra el poder! (p. 342).

El imaginario social, la alteridad en sombras, somos esa colectividad en abismo, sin mañana; espectador que confronta su propio tiempo en espectáculo realidad-ficción en confusas vertientes que lo rodean: vida-muerte, alteridad-transfiguración de lo humano, sociedad, sustancia estética de lo negro, lo oscuro, lo grotesco, lo violento; un mundo Otro en el que conviven personas y personajes en la vida y el arte como ¿ficción, espectáculo, representación o simulacro de lo real? 
Entonces, ¿existe supervivencia en la incertidumbre? El espectador a conciencia o sin saberlo, a punto de ser devorado por la Bestia del Siglo no se conforma con ser "entretenido". El mundo lo atropella de forma brutal, pierde la vida, los seres amados, vive en ella o le teme a la miseria material y humana. El día lo trastoca en agotamiento, cansancio, las falencias de subsistencia.

¿Es suficiente ese simulacro de realidad? No, necesita recobrar la realidad perdida, aun cuando esta sea brutal. Necesita verdad, sentido. Necesita verle la cara al monstruo en toda su dimensión.

La única manera en que sería posible disfrutar la violencia real es si esta fuera presentada en forma de espectáculo, como algo que ha sido intervenido hasta convertirse en algo que puede ser consumido. De otra manera, disfrutar la violencia real sería abandonarnos en nuestra propia crueldad, satisfacer nuestros más bajos instintos (Serrano, 2014, p. 36).

Se puede decir que el espectador actual solicita una violencia para ser apreciada como espectáculo, que se desnaturaliza para su disfrute porque es intervenida y preparada, "En él impera la violencia, proliferan los gestos de desprecio y de burla, incluso los insultos más broncos. Y el espectador, encuentra en ello su disfrute" (González y Torres, 2017). Como en el caso de las peleas de boxeo, que son transmitidas por diversos medios de comunicación y no producen ningún asombro o repudio al espectador, porque son aceptadas como espectáculo, y en la que se ha mediado la visión del sujeto como héroe y luchador, además se prepara a quien disfruta por medio de anuncios, apuestas y euforia, de forma tal que se vea como mero entretenimiento y no como barbarie.

Consciente de la prevalencia de la violencia en la experiencia del espectador es el teatro de Gustavo Ott una representación ficticia de ella, es así como escuchamos violencia en los parlamentos de sus personajes, que podemos ver en sombras, monstruos ocultos, amenazantes, angustia, miedo, crímenes, policías, corrupción, la vida en el sueño del espectáculo, la muerte, la negación del Otro, el poder que domina y silencia al Otro.

ABRIL: Tres balazos le dio a mi marido. En el pecho. Tres. Él venía del trabajo, subiendo a su casa por el camino peligroso y ahí se encontró con ese asesino. ¿Qué le pidió? Dinero. Quería dinero. Para comprar drogas, para gastarlo en armas, o simplemente le pidió dinero porque le dio la gana. Le quitaría unos billetes, no muchos, porque nosotros no tenemos nada. Nosotros somos tan pobres como el que más. Y entonces, cuando le quitó la cartera y el reloj y hasta los zapatos, entonces sin razón alguna, le pegó tres disparos (Ott, 2010, p.18).

A este dramaturgo lo abruman los temas y la realidad, son inimaginables, no hay reglas. Por ello, se apropia en sus obras representadas como espectáculo, del género negro 
en el arte que se conoce en general referido al cine: film noir, en francés que traducido al español sería cine negro.

La crítica cinematográfica describe este género de manera imprecisa tomando características de otros géneros como cine o novelas de gánster, policiales, cine social... Giran en torno a hechos delictivos y criminales tenebrosos, prostitución y tragedia. Estas características que define la crítica del cine son extendidas a otras manifestaciones artísticas, como la literatura y el teatro. Se observa en él corrupción, asesinatos, un hecho difícil de investigar, por cuanto los personajes, tanto los presuntos criminales como los investigadores, se confunden con el medio; son héroes también oscuros, que terminan involucrados en el crimen que pretenden descubrir. No llegan a alcanzar el halo de héroes épicos de otros géneros, a los que estamos acostumbrados a tipificar como semidioses.

Lo negro, desde la ficción, por más al límite que llegue, con sus recursos visuales, narrativos, de sombras, metáforas, música... en una representación que se tipifica como neorrealista, puede llegar al clímax del suspenso que no se confundirá con la realidad real; pues, allí saldrá la ficción en defensa del arte.

Ott con el género negro y la violencia, presenta un destino estético, cuenta una historia que como constante explora el mundo desde el espectáculo, con la "santificación" de los medios de comunicación como voz de Dios en la conciencia social en la que se mezclan la realidad y ficción, en superposiciones de mito y realidad en las que entran a la escena técnicas, símbolos, metáforas que se crean a partir del tema, significado y puesta en escena de una sociedad recreada.

\section{CONCLUSIONES}

Los anuncios de tiempos nuevos en las artes del espectáculo se comenzaron a notar cuando aparecieron en la cultura de masas escritores, cineastas, nuevas televisoras. Todos, a su vez, modificando a la televisión de masas que ya no contaría historias con la misma simpleza que las había contado siempre. La distracción, el pasatiempo y la socialización pasó a ser el gran fenómeno de un nuevo mundo que inició el protagonismo colectivo e individual: Internet. Se entrenó un nuevo espectador de cine, TV y, en consecuencia, un nuevo espectador para el teatro. Esto significó cambios en la cultura; en efecto, es verdad que ahora la sociedad es espectadora entrenada, también arrastra conflictos con lo incierto, el futuro, la existencia.

Gustavo Ott (1963) es un dramaturgo hijo y ejemplo de estos nuevos tiempos, del siglo XXI, se asume con la responsabilidad que identifica a un artista en constante búsqueda, una vasta cultura y en una inspiración constante que sale caminando desde su barrio, su país, al contexto universal, se reconoce en sus obras un dialogismo de conciencias Yo-Otro, profundidad en los temas; sustancia estética para el teatro y la vida. 
El teatro para este autor está concebido para un espectador entrenado por el nuevo cine, la nueva novela, las novísimas artes plásticas y hasta mucha televisión mundial. No crea la imaginación sin responsabilidad. Su teatro es intercambio de conciencias entre el Yo y el Otro con quien comparte sueños, conocimientos, experiencias, estudios, técnicas, creatividad. Convencido de que el espectador sabe que su mundo está ocupado por la barbarie; y busca, en su angustia, compañía que lo conmueva en su sueño.

Por tanto, el dramaturgo resalta que: "El Espectador madura, por estos días, antes que el arte y muy en particular, antes que el artista de la escena contemporánea... su sueño es tanto mi responsabilidad como la suya por haber soñado" (Ott, 2009). Sus obras no carecen de las formas (técnicas, medios de comunicación, cine) y plantean el Espectáculo como dimensión existencial del hombre en la nueva sociedad. Sus signos inequívocos están en sus temas, conflictos y puestas en escena.

De modo que el teatro de Gustavo Ott es un aporte valiente y comprometido a la identidad cultural, en tiempos de decadencia de espacios, oportunidades y compromisos. La globalización, el sistema político, el miedo y la delincuencia nocturna anulan creadores, espectáculo y espectadores en Venezuela y Latinoamérica. Ott ha saltado todas las dificultades y barreras idiomáticas, conocimientos, teorías, geografías del mundo. Un venezolano universal en tiempo, espacio e innovaciones. Universales del cine, la literatura y el teatro son maestros, a quienes admira y sigue; entre ellos: Dereck Walcott, Borges, Bolaños, Javier Marías, Jesús Soto, Tony Kushner, Coetzee, Quentín Tarantino, Iñárritu, Harold Pinter. En sus conocimientos y admiración tiene a sus maestros Cabrujas y Santana, quienes destacaron en la generación de ruptura y consolidación del nuevo teatro venezolano.

Es importante colocar esta opinión del autor, para comprender mejor la dimensión de Gustavo Ott como ser humano, ciudadano y creador, frente a la fatiga y alejamiento de la responsabilidad que padece el teatro venezolano y latinoamericano en el nuevo siglo:

...el secreto a voces que no queremos oír en los escenarios es que el espectador entrenado ya no pide entretenimiento, no desea combatir el stress, ya no le interesa evadirse. El espectador, donde antes pidió Efecto, hoy demanda Sentido. Busca un creador que, desde las bienales de arte Sao Paolo y Venecia a los festivales de cine Sundance, Cannes y hasta los Óscar, entienda que la belleza es, fundamentalmente, ética de combate, resistencia hasta la muerte y denuncia desesperada (Ott, 2009) (La negrillas son nuestras).

\section{OBRAS CITADAS}

Bajtin, Mijaíl (2000). Yo También Soy. Ciudad de México; Taurus. (1982). Estética de la creación verbal. México; Siglo XXI editores.

Debord, Guy (1967). La sociedad del espectáculo. Revista de observaciones filosóficas. Madrid. 
Fernández-Cozman, Camilo (2017). "El estilo separativo, la inteligencia figural y el etnocentrismo en la civilización del espectáculo de Mario Vargas Llosa”. Revista Acta literaria 54: 187-195. Disponible en: https://dx.doi.org/10.4067/S071768482017000100187 [Consulta: 2018, Junio 22].

González, Jesús y Torres, Lorena (2017). "La absorción de la política por el espectáculo de lo real. Estudio de caso: El Objetivo". Revista Latina de Comunicación Social 72: 1689-1750. Disponible en: http://www.revistalatinacs.org/072paper/1241/91es.html [Consulta: 2018, Diciembre 10].

Kant, Immanuel (1984). Crítica de la razón pura. Barcelona: Ediciones Orbis.

Mujica, Bárbara (2005). "Los cócteles dramáticos de Gustavo Ott". [Entrevista personal]. Revista Américas. Disponible en: http://www.gustavoott.com.ar/ documentos.php?c=2 [Consulta: 2014, Enero 20].

Ott, Gustavo (2013). El hombre más aburrido del mundo. [Blog en línea] Disponible en: http://www.gustavoott.com.ar/obrases.php [Consulta: 2014, Diciembre 10].

— (2010). Lírica. [Blog en línea] Disponible en: ttp://www.gustavoott. com.ar/obrases.php [Consulta: 2012, diciembre 6].

_ (2009). "El entretenimiento ha muerto". Revista de teatro Celcit. Argentina, Edición Agosto. Nro. 35/36: 41-52.

— (1996). Fotomatón. [Blog en línea] Disponible en: http://www.gustavoott. com.ar/obrases.php [Consulta: 2012, Julio 3].

Serrano, Arturo (2014). El cine de Quentin Tarantino. Una aproximación a la estética de la violencia. Caracas: Universidad Católica Andrés Bello.

Vargas Llosa, Mario (2012). La civilización del espectáculo. Venezuela: Santillana C. A.

Zuluaga, Esnedy (2016). "Los idiotismos de la modernización sin modernidad: un acercamiento a la dinámica urbana de principios de siglo XX en Colombia a partir de suenan timbres de Luis Vidales". Revista Alpha No43: 75-92. Disponible en: https://scielo.conicyt.cl/pdf/alpha/n43/art_06.pdf [Consulta: 2018, 2 febrero]. 